http://jmscr.igmpublication.org/home/ ISSN (e)-2347-176x ISSN (p) 2455-0450 crossref DOI: https://dx.doi.org/10.18535/jmscr/v7i8.148

\title{
Analysis of the Common Causes of Blood Donor Deferral in a Tertiary Care Hospital Indore: A Single-Center Study
}

\author{
Authors \\ Dr Zoya Khan ${ }^{1}$, Dr C.S. Chhatrasal*2 ${ }^{2}$, Prof. Dr Ashok Yadav ${ }^{3}$, Dr Pankaj Shinde ${ }^{4}$ \\ ${ }^{1}$ Resident Medical Officer in Department of Pathology, Mahatma Gandhi Medical College, Indore, \\ Madhya Pradesh, India \\ ${ }^{2}$ Associate Professor, Department of Pathology, Mahatma Gandhi Medical College, Indore, \\ Madhya Pradesh, India \\ ${ }^{3}$ Department of Pathology, Mahatma Gandhi Medical College, Indore, Madhya Pradesh, India \\ ${ }^{4}$ Associate Professor, Department of Pathology, Mahatma Gandhi Medical College, Indore, \\ Madhya Pradesh, India \\ *Corresponding Author \\ Dr C.S. Chhatrasal
}

\begin{abstract}
Background: We aimed to conduct a retrospective study in order to statistically analyze the common causes for blood donor rejection in a tertiary care center at Indore according to the American Association of Blood Banks. The analysis of the pattern of deferral and interventions to bring back deferred donors when possible could be a strategy for long-term retention of motivated blood donors.

Subjects and Methods: A sample of 2492 rejected donors was randomly selected from a single blood bank between June 2016 to July 2019. The evaluation of blood donors was medical according to the personal history questionnaire and a medical examination done before the blood donation proceeded.

Results: The causes of deferral were categorized into three main categories: personal factors, examination and medical history. The most common personal cause of deferral was alcohol( $7.5 \%)$; however, the most common medical examination cause of deferral was anaemia (36.3\%)Concerning the medical history, the commonest cause was medication.(13.3\%).

Conclusion: Anaemia (36.3\%), medication (13.3\%) and alcohol (7.5\%); were the major causes of rejection in this study. Similarities and variations between the commonest causes of blood donor rejection may be due to the differences and similarities in the geographic area and in the cultural, educational and socioeconomic factors.

Keywords: Donor questionnaire, blood transfusion, safe blood.
\end{abstract}

\section{Introduction}

Blood donation is considered as an important practice in emergency conditions in medicine ${ }^{[1]}$. The need for blood is universal; however, millions of patients who may need transfusion do not have timely access to safe blood, and there is a major imbalance between the developing and developed countries in access to safe blood. Safe blood transfusion is a major concern that needs the application of science and technology to blood processing and testing, as well as social efforts to promote blood donation by sufficient numbers of 
volunteers who are healthy and are at low risk of infections that can be transmitted to the recipients of their blood. 2 The WHO Global Data indicated that $\square 98$ million blood donations are collected annually from 168 different countries. Around 1.6 million units were discarded due to the presence of infections such as HIV, hepatitis B and C, syphilis and herpes. In addition, at least 13 million donors were deferred due to having the risk of infection that could be transmitted through blood, a preexisting medical disease or anemia.3 Due to this, blood donor selection is a crucial step for blood transfusion safety, designed to safeguard the health of both recipients and donors.4 Blood donor eligibility is determined by medical interview, based on national guidelines for donor selection.5 The key tool for blood donor selection would be a "donor questionnaire" that would assess a donor's history and health that would help assess if the donor has any risk for having any infection that could be transmitted by the blood and furthermore has no suitable screening test. After that, a confidential interview is conducted between the donor and a member staff to ensure that all questions are answered relevantly. 3 In this study, we aimed to analyze the common causes for blood donor deferral in a tertiary care center at Indore according to the American Association of Blood Banks.

\section{Material and Methods}

This cross-sectional study was conducted at Mahatma Gandhi Medical College Indore (M.P) between June 2016 to July 2019. Data were held confidentially. Informed consent was not needed because the study was conducted retrospectively. Data were collected from the records in the blood bank and then analyzed. A sample of 2492 deferred donors was selected. Data were entered using Google Forms and then further analyzed by Microsoft Excel. Data were presented as numbers, pie charts and percentages. The evaluation of all blood donors who came to apply for donation was done according to a questionnaire that included questions of personal history of behaviors, traveling and medical conditions. After that a medical examination of the intended blood donor was carried out consisting of weight, height, vital signs and hemoglobin. The American Association of Blood Bank's guidelines and the blood bank's guidelines were used for either selection or rejection. All the donors were educated and the process of donation was fully explained to them. The donors were confidentially requisitioned orally about certain risk behaviors, history of traveling and many other conditions that would eventually affect the recipient's safety. All this was done to make sure of the donor's eligibility.

\section{Result}

This study was conducted on 2492 selected deferred blood donors. Most of those who were rejected were males $(1734$ [69.5\%]) and the rest were females (758 [30.4\%]), as shown in Table 1. Their ages ranged from 18 to 60 years, with most of them aged between 20 and 30 years (1632 [65.5 $\%]$ ), as shown in Table 2.The deferral of blood donors was categorized under three

main categories: personal causes, causes due to significant medical examination and other causes due to a donor's history. Table 1 also illustrates that $1355(54.3 \%)$ were deferred due to significant medical examination, $871 \quad(34.9 \%)$ due to significant history and only $266(10.6 \%)$ were rejected due to personal issues. Concerning the personal causes for deferred blood donors, the commonest was that the intended blood donor was having alcohol addiction, as shown in Table 3.Regarding the examination causes for rejection, the commonest was that the donor had low hemoglobin ie, <12.5 gm \%905 (36.3\%)followed by fever (197 [7.9\%]), high blood pressure (71 [2.8\%]) and underweight (86 [3.5\%]), as shown in Table 4.A donor's previous history of some personal behaviors, medical conditions or even traveling was also taken in to consideration as a cause of refusal. The most frequent was that the donor was under medication for some chronic illness (329 [13.3\%]), followed by antibiotic ingestion (243 [9.8\%]), previous donation (80 
[3.2\%]) and having some illness like jaundice, typhoid (72 [2.9\%]), as shown in Table 5. Least causes of rejection in this study included dental procedure (12 [0.5\%]), history of surgery (11 [0.4\%]) and sexually transmitted diseases (18 [0.7\%]). Other least common purposes in this category are mentioned in Table 5 .

Table 1 Gender distribution and categories of causes of deferral

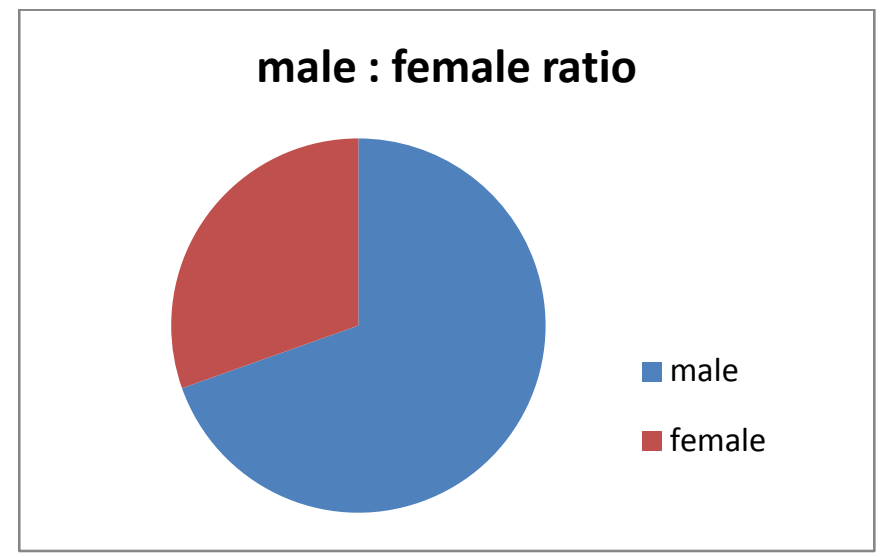

\section{Category of causes of deferral}

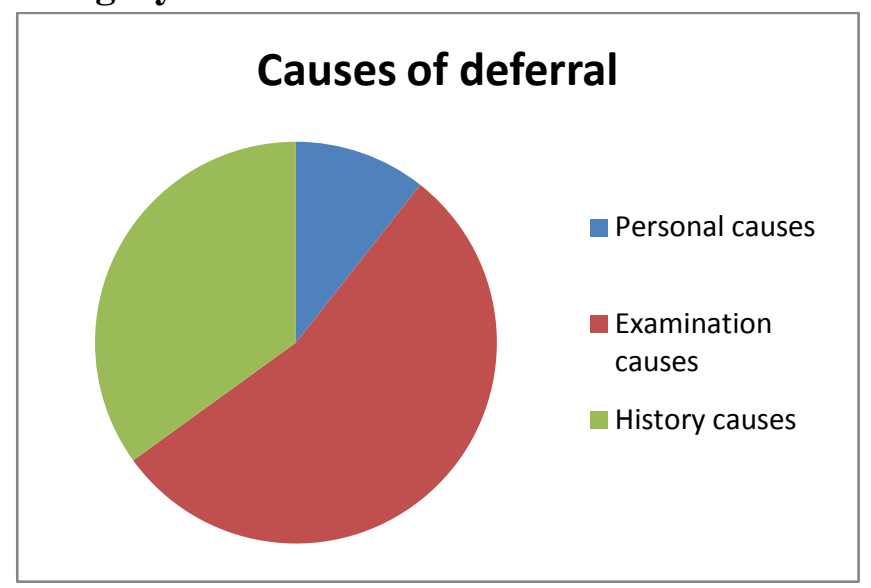

Table 2 Age ranges of the deferred donors

\begin{tabular}{|l|c|}
\hline Age ranges in years & Age ranges in years \\
\hline $18-20$ & $70(2.8)$ \\
\hline $21-30$ & $1632(65.5)$ \\
\hline $31-40$ & $647(26.0)$ \\
\hline $41-50$ & $117(4.7)$ \\
\hline $51-60$ & $26(1.0)$ \\
\hline Total 2492 (100) & Total 2492 (100) \\
\hline
\end{tabular}

Table 3 The personal causes for blood donor deferral

\begin{tabular}{|l|c|}
\hline Personal Causes & No. of deferred (\%) \\
\hline Less sleep hours & 79 \\
\hline Alcohol consumption & 187 \\
\hline Total 266 (10.6\%) & Total 266 (10.6\%) \\
\hline
\end{tabular}

Table 4 The examination causes for blood donor deferral

\begin{tabular}{|l|c|}
\hline Examination causes & No. deferred (\%) \\
\hline Low blood pressure & $42(1.7)$ \\
\hline Low hemoglobin & $905(36.3)$ \\
\hline High blood pressure & $71(2.8)$ \\
\hline Low weight & $86(3.5)$ \\
\hline Fever & $197(7.9)$ \\
\hline Palpitations & $54(2.1)$ \\
\hline Total 1355 (54.3\%) & Total 1355 (54.3\%) \\
\hline
\end{tabular}

Table 5 A donor's history, which caused deferral

\begin{tabular}{|l|c|}
\hline History & No. of deferred (\%) \\
\hline On Antibiotic & $243(9.8)$ \\
\hline Dental procedure & $12(0.5)$ \\
\hline Operation & $11(0.4)$ \\
\hline Donated in past & $80(3.2)$ \\
\hline On medications & $329(13.3)$ \\
\hline Heart/lung disease & $26(1.0)$ \\
\hline Sexually transmitted disease & $18(0.7)$ \\
\hline Tattoo in the past 3 months & $31(1.2)$ \\
\hline Common cold & $49(1.9)$ \\
\hline Sick(jaundice , typhoid etc.) & $72(2.9)$ \\
\hline Total 871 (34.9\%) & Total 871 (34.9\%) \\
\hline
\end{tabular}

\section{Discussion}

Billions of blood groups and their products are transfused every year all around the world. In the South East Asian, about 13.6million units of red blood cells and whole blood were transfused "altruistic intentions", and they believe themselves as healthy entities, though some of these contributors may be unfit to donate blood. Hence, it is the duty of the blood bank centers to recognize these unfit donors and defer them provisionally or permanently. The study laid emphasis on determination of rate and causes of deferral of donors to work as strategy making effort for recruitment and retention of blood donors both regionally and nationally.

In our study, it has been found that low hemoglobin as a cause of blood donor refusal accounted for $34.4 \%$ in this study. This could be due the menstrual loss of blood in the childbearing age group and consumption of low-iron diet and cultural habits may be due to the different geographic areas and the cultural, educational and socioeconomic factors. 
Another category consists of $13.3 \%$ who were refused because of taking medication for some chronic illness.

It has also been found in our study that $7.5 \%$ were deferred due to alcohol consumption. We also found that inadequate sleep was also one of the causes of deferral $(3.1 \%)$. This may reflect the unhealthy sleeping habits in the Indian population. Our study showed that $1.7 \%$ was rejected due to low blood pressure. The low blood pressure could be due to the anxiety experienced prior to donation. Various studies have shown that low blood pressure is associated toanxiety. ${ }^{14,17}$

Other studies also showed that sore throat or having a cold or high temperature was also a common cause of deferral. ${ }^{19}$

Analyzing all the data it has been concluded that it is important to analyze the donor deferral criteria in specific demographic areas in the categories described unique to the area so as to develop a safe pool of blood donors as well to bring back donors deferred due to temporary causes and minimize loss of blood donors and keep them motivated. Regular blood donors make the best group of blood donors, and low hemoglobin levels were the most important reasons for temporary deferral in most studies and in this study too. Thus, combining anemia prevention and treatment in donor recruitment strategies could help regain the donors and develop a healthy blood donor pool. Efforts to increase the hemoglobin in the repeat donors has the potential to improve the donor retention and increase overall blood safety. ${ }^{[15,16]}$ Donor selection through structured questionnaires is an important prerequisite for safe donor recruitment and if carried out as a uniform policy may even affect the prevalence data as donors with transfusion-transmitted infections would be excluded even before donating a unit of blood. There is a need to assess the deferral pattern in different regions for recommending revisions in donor selection criteria as well planning strategies for re-entry of donors deferred temporarily to be brought back to regular donor pool.. Raising general awareness for blood donation and encouraging related donors to become regular donors may help increase the number of voluntary donations. The analysis of the pattern of deferral and interventions to bring back deferred donors when possible could be a strategy for long-term retention of motivated blood donors.

\section{Conclusion}

Anaemia (36.3\%), medication (13.3\%) and alcohol $(7.5 \%)$; were the major causes of rejection in this study. Similarities and variations between the commonest causes of blood donor rejection may be due to the differences and similarities in the geographic area and in the cultural, educational and socioeconomic factors.

\section{Acknowledgments}

We would like to take this opportunity to express our profound gratitude and deep regards to our teachers Prof. Dr.Ashok Yadav who all provided us with guidance throughout our journey while working on this research. Nevertheless, their supervision, insight and expertise which greatly assisted the research. Great thanks to Miss Kavita and Miss Afsana for their assistance during data collection.

\section{Disclosure}

The authors report no conflicts of interest in this work.

\section{References}

1. Tariq S, Tariq S, Jawed S, Tariq S. Knowledge and attitude of blood donation among female medical students in Faisalabad. J Pak MedAssoc. 2018;68(1):65-70.

2. Department of Essential Health Technologies Blood Transfusion Safety Unit. Universal Access to Safe Blood Transfusion. Geneva: World Health Organization; 2008.

3. World Health Organization. Blood Donor Selection: Guidelines on Assessing Donor 
Suitability for Blood Donation. Geneva: World Health Organization; 2012:16-23.

4. Gillet P, Neijens E. An original approach to evaluating the quality of blood donor selection: checking donor questionnaires and analyzing donor deferral rate. Front Med. 2018;5:74.

5. Katz L, Strong DM, Tegtmeier G, Stramer S. Performance of an algorithm for the reentry of volunteer blood donors deferred due to false positive test results for antibody to hepatitis B core antigen. Transfusion. 2008;48(11):2315-2322.

6. Gonçalez TT, Sabino EC, Schlumpf KS, et al. Analysis of donor deferralat three blood centers in Brazil. Transfusion. 2013;53(3):531-538.

7. Arslan Ö. Whole blood donor deferral rate and characteristics of the Turkish population. Transfus Med. 2007;17 (5):379-383.

8. Bahadur S, Jain S, Goel RK, Pahuja S, Jain M. Analysis of blood donor deferral characteristics in Delhi, India. Southeast Asian J Trop MedPublic Health. 2009;40(5):1087-1091.

9. Lim JC, Tien SL, Ong YW. Main causes of pre-donation deferral of prospective blood donors in the Singapore Blood Transfusion Service. Ann Acad Med Singapore. 1993;22(3):326-331.

10. Al Shaer L, Sharma R, Abdulrahman M. Analysis of blood donor predonation deferral in Dubai: characteristics and reasons. J Blood Med.2017;8:55-60.

11. Bashawri LA. A review of predonation blood donor deferrals in a university hospital. J Family Community Med. 2005;12(2):79-84.

12. Abdelaal M, Anwar F. Analysis of blood donor deferral in Jeddah, Saudi Arabia: characteristics and causes. J Pak Med Assoc. 2016;66(11): 1392-1395.
13. aabb.org [homepage on the Internet]. Bathesda: AABB Blood FAQ.2019. Available from: http://www.aabb.org/tm/Pages/bloodfaq.as px. Accessed August 18, 2017

14. Hildrum B, Mykletun A, Holmen J, Dahl AA. Effect of anxiety and depression on blood pressure: 11-year longitudinal population study. $\mathrm{Br} \quad \mathrm{J}$ Psychiatry. 2008;193(2):108-113.

15. Newman BH. Adjusting our management of female blood donors: The key to an adequate blood supply. Transfusion 2004;44:591-6. [PubMed] [Google

Scholar]

16. Qureshi NA, Ali GI, Abushanab TS, et al. History of cupping (Hijama): a narrative review of literature. $\mathrm{J}$ Integr Med. 2017;15(3):172-181.

17. Fowler PM, Paul DJ, Tomazoli G, Farooq A, Akenhead R, Taylor L.Evidence of suboptimal sleep in adolescent Middle Eastern academy soccer players which is exacerbated by sleep intermission proximal to dawn. Eur $\mathbf{J}$ Sport Sci. 2017;17(9):1110-1118.

18. Halperin D, Baetens J, Newman B. The effect of short-term, temporary deferral on future blood donation. Transfusion. 1998;38(2): 181-183.

19. Nordenberg D, Yip R, Binkin NJ. The effect of cigarette smoking on hemoglobin levels and anemia screening. JAMA. 1990;264(12):1556-1559.

20. Madani TA. Sexually transmitted infections in Saudi Arabia. BMC Infect Dis. 2006;6(1):3.

21. Abdalla SI, Malik EM, Ali KM. The burden of malaria in Sudan: incidence, mortality and disability-adjusted life-years. Malar J. 2007;6(1):97. 